\title{
The Impact of Education on Child Abuse Prevention
}

\author{
Ha Thi Hai Do* \\ Faculty of Management Science, National Economics University \\ No. 207, Giai Phong Street, Dong Tam Ward, Hai Ba Trung District, Hanoi, 11616, Vietnam \\ Khanh Kim Nguyen \\ Program of Public Management and Policy (E-PMP) Intake 59, National Economics University \\ No. 207, Giai Phong Street, Dong Tam Ward, Hai Ba Trung District, Hanoi, 11616, Vietnam \\ Ha Phuong Pham \\ Program of Public Management and Policy (E-PMP) Intake 59, National Economics University \\ No. 207, Giai Phong Street, Dong Tam Ward, Hai Ba Trung District, Hanoi, 11616, Vietnam
}

\begin{abstract}
This research investigates the impact of education on child abuse prevention in Vietnam by using Vietnamese government's reports $(2012-2019)$ on child abuse. In order to analyze the impact of education on child abuse prevention, this study focuses on reviewing the previous policies in preventing child abuse, surveying three main determinants of parents, teachers and children and testing the data collected from the survey. The result shows that education plays an important role in improving the ability to take actions against child abuse. Some recommendations to parents, teachers, children and the government are also proposed for encouraging improvements in child abuse prevention education.
\end{abstract}

Keywords: Child Abuse Prevention, Education, Vietnam

DOI: $10.7176 / \mathrm{EJBM} / 12-20-09$

Publication date:July $31^{\text {st }} 2020$

\section{Introduction}

In the context of globalization, Vietnam is facing socio-economic changes, especially in the child welfare system. In 2019, child abuse issue was acknowledged by the society and was in need of solutions immediately. In order to prevent the rising in child abuse cases, the government established new policies, regulations and collaborated with international organizations to educate, prevent and reduce the number of child abuse cases. According to the government's reports (year), among $58.2 \%$ of children who suffered from stress, there were $42.7 \%$ of children who were physically punished. The number of phone calls received to report about child trafficking was 764 phone calls from January 2019 to June 2019. National Child Protection Hotline 111 received more than 300,000 phone calls in first trimester of 2019 and 30 percentages of those was child sexual abuse cases. Although the number of child abuse cases decreased slightly in 2019 , there was still a warning to Vietnamese children's safe. Furthermore, the child abuse knowledge and self-protection skills of Vietnamese were still questioned. In addition, there are five difficulties that the government has to face up to (i) the limitations in Children Law lead to the lack of adaptation for emergency cases; (ii) the rate of child abuse cases increases; (iii) national programs have difficulties in resource and implementation system; (iv) staff are lack of skills, implementation methods and having unclear payment policy; (v) services for children are not suitable for the recent conditions.

Vietnam's government has announced "Taking Actions for Children's Month" as an activity to enhance the child abuse prevention. Protecting children from child abuse through educating and advertising will create a solid foundation, which requires detail plans with clear contents and methods. This research aims to analyze and evaluate the reality of child abuse prevention education in order to recommend solutions.

Child abuse prevention education, which is a process of applying educational methods to enhance the awareness about children and child abuse, including three forms: (i) in school, (ii) in home and (iii) in public. Firstly, school is known as the second house for children. To them, teachers and friends are the bridges to the outside world. Therefore, school staffs play an important role in reducing risks for children, especially abusing children. To optimize these potentials, one should learn about (i) analyzing child abuse and report suspect cases; (ii) completing required report's procedures; (iii) supporting child abuse victims and children effectively by accessing public services; and (iv) understanding the purposes and contents of child abuse prevention. So do students, they need to fulfill both knowledge and soft skills about child abuse to be able to recognize and take actions when it comes to child abuse. Secondly, parents have the strongest connection with children and change the face of child abuse., therefore, parent education based on the theory of preventing child maltreatment by giving care, staying positive and sustainable in raising children and creating a safe environment in the house. Parent education includes 3 levels: mass, groups and individuals. In mass level, child abuse campaigns will be created to provide overall information about child abuse (definitions, forms, up to date statistics, etc.). In group level, parents 
will be grouped to share their confusion, worries and find suitable solutions. This level not only helps address difficulties but also extends the social circle for parents. On an individual level, this level will be applied for newborn/pregnancy/child abused families. By gaining trust and developing positive relationships in families, the educators will have a chance to analyse internal and external factors that affect children and parents. Finally, public education contains a huge impact on society through media and research activities to educate about child abuse, and to change the perspective about child abuse.

The study aims for systematizing theoretical basis and examining the status of the education on child abuse prevention's impacts in Vietnam in order to recommend solutions on improving the quality of child abuse prevention education. This study targets on the impacts of child abuse prevention education to child abuse and states four questions to answers as below:

(i) What is "child abuse" and how many types of child abuse are there?

(ii) What is education on child abuse prevention? How many types of child abuse prevention education are there?

(iii) How does education on child abuse prevention impact on child abuse status in Vietnam?

(iv) How to improve child abuse status through education?

\section{Literature review and theoretical mode}

\subsection{Child abuse}

According to Phfohl (1977), child abuse was forgotten in the society in the last decade because of the law system and the old-fashioned education method. Until 1957, with the contribution of medicine, child abuse issue regained attention from the public. Child abuse was defined as "clinical condition" existing as an "unrecognized trauma". It defined the deviance of its "psychopathic" perpetrators as a product of "psychiatric factors" representing "some defect in character structure". Over time, child abuse became a social problem, which led to many related studies. O'Brian \& Lau (1995) defined child abuse in terms of "the psychological and physical harm done to a child that endangers or impairs a child's health and development". In addition, the African Network for Prevention and Protection Against Child Abuse and Neglect (ANPPCAN) defined child abuse as "the intentional, unintentional or well intentional acts which endanger the physical health, emotional, moral and the educational welfare of children."

At the beginning, child abuse was known as physical abuse - the foundation and basic clues to recognize child abuse cases. Over time, child abuse had been categorized into many different perspectives. According to Meadow (1989), child abuse was divided into four types: (i) Physical abuse - includes injuries on skin, eyes, ears, or bruises, bite marks as a result of shaking, burning, beating that harm the child. (ii) Neglect - failure to provide love, care, protection from dangers or create a healthy and safe environment for children to develop. (iii) Sexual abuse children involve in sexual activities even though they have not had the ability to be aware of and distinguish whether to agree or not. The levels of sexual abuse come from fondling to masturbating and raping when children are forced to take sexual pictures, videos. (iv) Emotional abuse - with no specific definition. A few years later, Finkelhor \& Korbin cited a definition about emotional abuse as "the willful destruction or significant impairment of a child's competence through such acts as the punishment of attachment behavior, punishment of self-esteem, and punishment of behaviors needed for normal social interaction". There were six types of emotional abuse: (a) Rejecting - to reject a child's abilities or desires repeatedly, (b) Isolating - to deprive a child's connection with the society and basic needs for developing healthily, (c) Terrorizing - to threaten to abandon or hurt the child, (d) Ignoring - lack of caution and fulfill the child's needs in time, (e) Corrupting - to force a child to join unusual activities that can harm the ability to connect with the society, (f). Adultifying - to give unsuitable demands to the child. In 2020, Umobong mentioned another type of child abuse, "child exploitation", which is related to child employment or trafficking including forcing children to work for making profits. Child exploitation is a process of employing children with unequally payment, careless attitude to children's health.

\subsection{Impact of education on child abuse prevention}

The "KAP" model represents Knowledge, Attitude and Practices, which is used to diagnose a community's educational ability. To define, "Knowledge is ability of pursuing and using information, and by understanding, learning experience, and identifying the stuyding technologies. Attitude indicates the result of making reactions via some ways in some situations, and observes and explains based on the result of reaction or combine into one point of view. Practice indicates what knowledge and habit work together" (Librahim, 1995). The researchers conducted three different experiments and concluded that knowledge and attitude-practice combinations have a causal relationship with each other, and knowledge also affects the consistancy of the attitude-practice. Knowledge creates changes in attitudes, attitudes associated with a high complexity knowledge base will make changes in actions.

Education has been shown to have a positive effect on increasing the amount of knowledge. Alkhateeb et al. (1975) compared the different modes of education applied in a polyclinic. The results showed that all three methods brought an increase in awareness and knowledge for the experimental subjects. Another analysis of the influence 
of education on attitudes shows similar results. Rabinowitz and Zimmerli (1974) observed that the attitude of the experimental group about tobacco use had significant changes in the expected result. These changes occur in both smokers and non-smokers. Lutz (1975) stated that a change in an individual's assessment of the value of a particular object might not lead to a change in their attitude but a change in perception of one or more objects would. The objects would change the person's total attitude. As a result, the changes in attitude would lead to a change in actions because of the causal relationship between these two factors.

Child abuse prevention education enhances the awareness of child abuse, and changes the attitude and practice of the public. With parents and teachers, education will change the negative education method, being aware of the impact of physical punishments. To children, education will strengthen the knowledge and self-protection skills to prevent child abuse (Daro \& Donnelly, 2000).

The effect of child abuse prevention education includes: (i) Reducing the child abuse rates - by raising the awareness, strengthening the knowledge and changing the attitude, practice about child abuse of the public. According to Lutzker (2009), Triple P program, applied in many countries such as United Kingdom, United States, and Australia, has positive outcomes. Among 18 cities of South Carolina state, the number of child abuse cases is lower in Triple P program applied cities; (ii) Enhancing the knowledge and lower the risk of child abuse - according to the researchers, one of the main reasons leads to child abuse is the lack of suitable education method for children. Therefore, by educating about child abuse, all the parties can create a secure environment, healthy relationship between children and parents, children and teachers. Canavan (2014) mentioned that after participating in education on child abuse prevention programs, the number of parents who have mental illness reduces to 32 percentage; (iii) Providing more opportunities for children to develop healthier - Feldman (2014) mentioned that children develop healthier in Triple P program applied kindergartens (12 percentage) than no applied ones (3\%). Also, children were recognized to have an improvement in mental health, for example, emotional disorder decreases 29.7\%; hyperactivity disorder rates decrease $27 \%$; lack of self-control ability reduces $30 \%$ and contribution for social activities such as helping people increases $35 \%$.

From the above theories and practical research, we proposed a model that demonstrates the impact of education on knowledge, attitudes and behaviors on child abuse as below:

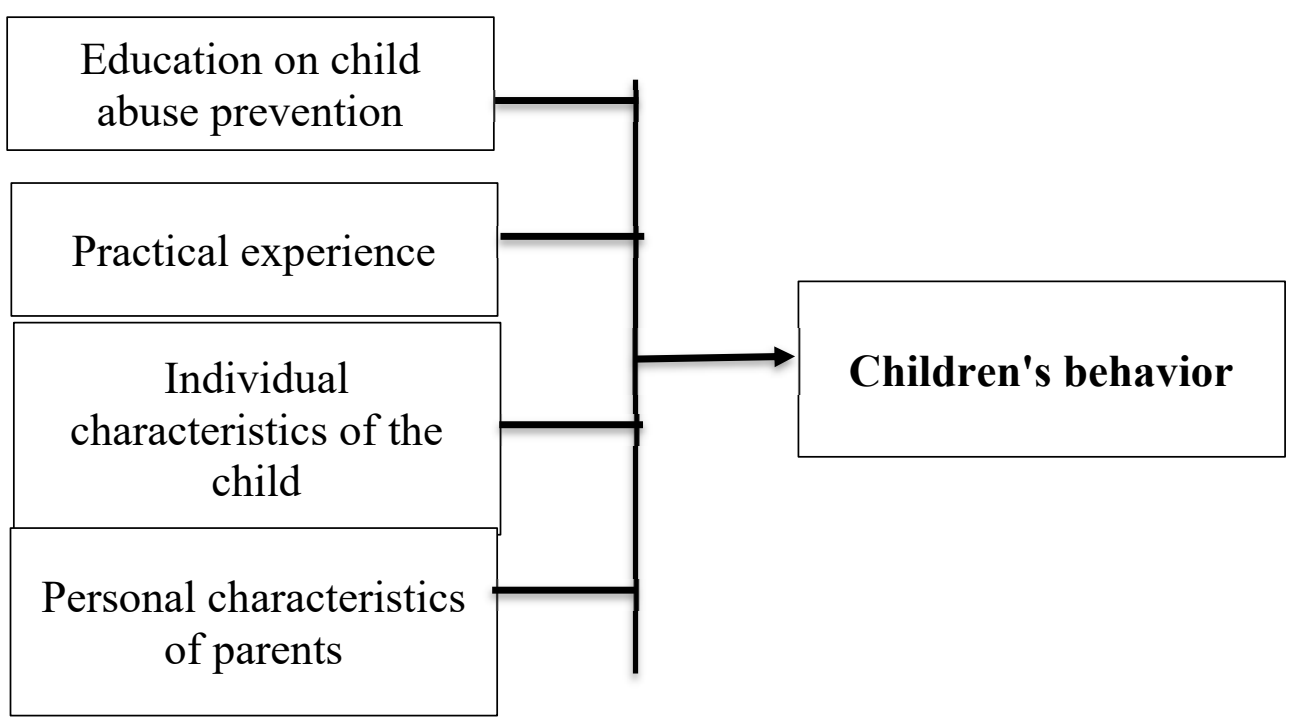

Figure 1: Research model

\section{Current situations in the context of Vietnam}

\subsection{Legal system to protect children}

Vietnam Constitution 2013 states that children are protected, cared for and educated by the State, family and society; be involved in child issues. It is strictly forbidden to abuse, abuse, mistreat, neglect, abuse, exploit labor and other acts that violate children's rights.

The State of Vietnam demonstrates its political commitment to building a comprehensive and comprehensive system of laws and policies on child protection, including the protection, care and education of children. The Law on Children fully stipulates the civil, political, cultural, social, economic rights of children, in harmony with the United Nations Convention and international standards on children's rights, specific provisions on child protection, prohibited children's rights violations and children's participation in children's issues in the spirit of the 2013 Constitution. The responsibility of the state, the family, the school and society to exercise children's rights is also stipulated in the Law.

In addition, child protection, care and education are provided for more than 20 other laws, such as the 2005 
Education Law (amended and supplemented in 2009), the Civil Code, the Criminal Code, the Labor Code, the Law on Marriage and Family, the Law on Prevention and Fight against Violence family force regulations in the direction of ensuring the best friendliness and best interests of children, and strictly handling acts of child abuse.

\subsection{Current situation of child abuse in Vietnam \\ (i) Sexual abuse}

Of the total of child abuse cases, up to $82 \%$ of the cases (equivalent to 1,269 cases) were cases of child sexual abuse with 1,233 cases, the number of abuses was 1,141 children. Analyzing by crime, the Ministry of Public Security said that in 2018 there were 425 cases of child rape, 606 sexual intercourse with children, 232 cases of child pornography and 271 other crimes; criminal handling 1,255 cases (accounting for 81\%) with 1,360 subjects (accounting for 81\%); Handling administrative cases 112 (accounting for 7.2\%) with 162 subjects (accounting for 9.7\%). Investigating and verifying 62 cases (accounting for 4\%) with 58 subjects (accounting for 3.5\%), the rest cases are suspended, not prosecuted. (Source: Ministry of Public Security, 2019)

According to the ASEAN report, there were 706,435 cases related to Vietnam in 2018 on images of videos of child sexual abuse online, ranked second in ASEAN, after Indonesia. Vietnam was assessed to only achieve 1/5 of the ICMEC 2018 assessment criteria for 161 countries and territories for CSAM issues, rated as one of the countries with low levels of online child protection.

\section{(ii) Child exploitation}

According to a report of the Government Steering Committee for Crime Prevention and Fighting, from 2012 to 2017 , functional forces organized rescue and received about 7,500 people who were victims of human trafficking. Reviewing trafficked victims, over $90 \%$ of trafficked victims are women and children (about $6.8 \%$ of the victims are young people, pupils, students). Over $98 \%$ of victims of trafficking abroad are estimated and over $80 \%$ of victims are from ethnic minorities, with less education, awareness, less access to information and difficult economic circumstances; more than $70 \%$ of the victims are either farming or unemployed; $37.2 \%$ were illiterate. (Source: Ministry of Labor, Invalids and Social Affairs, 2019)

\section{(iii) Physical abuse}

According to the Vietnam MICS 2014 report, for the majority of cases, households have incorporated child sanctions, reflecting the motivation of caregivers to control their behavior in every way possible. While $58.2 \%$ of children have experienced psychological stress, about $42.7 \%$ have been subject to physical punishment. The most severe form of physical punishment (hitting the child on the head, ears or face, or hitting the child hard and repeatedly) was generally uncommon, with $2.1 \%$ of children ever being severely punished. Boys are more physically punished $(48.5 \%)$ than girls $(36.6 \%)$. Differences in the basic characteristic groups are quite small. Children living in rural areas and in poor households often face at least one form of psychological pressure or physical punishment (Vietnam MICS Report, 2014).

\subsection{Education on child abuse prevention}

The 2016 Child Law states that agencies, organizations, educational institutions, families and individuals have the responsibility to take appropriate measures to ensure that children live safely and healthy; preventing, stopping and handling acts of child abuse

\section{(i) Education in schools}

Annually, the Departments of Education and Training of provinces and localities coordinate with schools to develop plans for law dissemination and education, deploy to all cadres, civil servants, officials, employees and students across the industry. The content of law dissemination and education is abundant, propagandizing and promptly propagating the Party's guidelines, the State's policies and laws; especially the newly issued documents, practically related to the life, labor and study of civil servants, officials, employees and students in the district. Thereby, bringing the work of law dissemination and education in the school into depth, practical and highly effective.

\section{(ii) Parenting education}

In recent years, programs to educate parents on the prevention and control of child abuse often focus on fostering child sexual abuse prevention skills for parents. The overall objective of fostering skills against child sexual abuse to parents is to help parents supplement, update and improve their knowledge and skills to prevent and combat child sexual abuse., create a healthy and favorable environment for children, and at the same time, ensure social stability. The content of fostering child sexual abuse prevention skills for parents is the system of knowledge and skills to prevent and combat child sexual abuse with the child's development requirements and development requirements of the commune festival; At the same time, it is suitable with the training needs and the actual level of parents in each locality. Regarding the training method, the training of child abuse prevention and control skills is usually carried out in three modes: (i) Concentration fostering according to long-term courses or short-term courses at a training facility; (ii) On-the-spot fostering means fostering the skills to prevent and combat child sex activities for parents at a certain location in the locality to ensure the necessary conditions of fostering skills to 
prevent and combat sexual abuse children and (iii) Distance training is also provided on the spot with the help of audiovisual devices.

In order to achieve the objective of fostering child risk prevention and fighting skills, it is necessary to coordinate all three methods to meet the parents' needs of fostering prevention and fighting skills.

(iii) Mass education

In the past time, the Ministry of Labor, War Invalids and Social Affairs has organized many national programs and forums for Children, the National Children Forum is held every two years, with the participation of many children from each province and city, to listen to their opinions, as well as educate them about their rights, skills to prevent and abuse children. In addition, the Ministry also organizes a Month of Action for children once a year for the purpose of educating the whole society, ensuring the rights of children as well as raising awareness and responsibility for the community in the matter protecting children from abuse.

\section{Research methodology}

4.1. Research sample

The study used a semi-structured questionnaire to collect data to analyze the factors that affect children's behavior when abused. The questionnaire will be sent directly and online via Google Survey to parents, teachers and children from February 13, 2020 to March 30, 2020. The study used 200 survey samples, the number of valid votes collected was 144/200. The team surveyed 144 children aged 11-18, categorized by gender (male / female), living area (urban / rural), individual characteristics of the child, and personal characteristics of parents. The survey was conducted with 03 target groups, including children, parents and teachers living in 02 urban and rural areas in 4 provinces / cities directly under the Central Government, which are representative provinces. for the North, Central and South.

\subsection{Research model}

The Probit model is used to estimate the model of education-training factor analysis to child abuse prevention. Probit probability regression model equation has the form:

Inside:

$$
\mathrm{Yi}=\beta \mathrm{o}+\beta_{1 \mathrm{i}} * \mathrm{X}_{1 \mathrm{i}}+\beta_{2 \mathrm{i}} * \mathrm{X}_{2 \mathrm{i}}+\beta_{3 \mathrm{i}} * \mathrm{X}_{3 \mathrm{i}}+\beta_{4 \mathrm{i}} * \mathrm{X}_{4 \mathrm{i}}+\varepsilon_{\mathrm{i}}(*)
$$

- Y dependent variable: child behavior when abused

$+\mathrm{Y}=1$ : Immediately notify parents and surrounding adults/Immediately notify government agencies

$+\mathrm{Y}=0$ : Do nothing

- The independent variables Xi: showing factors affecting child abuse prevention and control acts, including:

$+\mathrm{X}_{1 \mathrm{i}}$ is a group of individual characteristics of children, including: age, gender, place of residence and school.

$+\mathrm{X}_{2 \mathrm{i}}$ is a group of variables characteristic of parents of children: educational level, marital status.

$+\mathrm{X}_{3 \mathrm{i}}$ is a group of variables related to education on child abuse prevention and control:

$\checkmark \quad$ Ever heard of child abuse

$\checkmark \quad$ Having been educated citizen ethics

$\checkmark \quad$ Have been equipped with knowledge about child abuse

$\checkmark \quad$ Having been trained in skills to prevent and combat child abuse

$\checkmark \quad$ Having been taught about child abuse

$\checkmark \quad$ Having been taught self-defense skills

$+\mathrm{X}_{4 \mathrm{i}}$ is a group of variables related to practical experience

$\checkmark \quad$ Has been abused

- ßo: Coefficient of blocking

- $\varepsilon_{\mathrm{i}}$ : Random error

Analysis

The Probit model is known as the regression model whose dependent variables are discrete and only receive two possible values: 0 and 1. The probit model assumes that Child abuse prevention / action is affected by a potential variable. This latent variable is called the utility index I. The index variable is affected by explanatory variables:

$$
I_{i}=\beta_{1}+\beta_{2} X_{i}
$$

A child engages in child abuse prevention and control when this value of I exceeds a certain threshold temporarily called I*. This I* value is not known, but it is assumed to have a normal distribution. Probability for children to have acts of preventing and combating child abuse will have the form:

$$
P_{i}=P\left(I_{i}^{*} \leq I_{i}\right)=P\left(Z_{i} \leq \beta_{1}+\beta_{2} X_{i}\right)=F\left(\beta_{1}+\beta_{2} X_{i}\right)
$$

$\mathrm{F}$ function is a standard cumulative distribution function (CDF). Since $\mathrm{P}$ is the probability that children will engage in acts of child abuse prevention, we must calculate the inverse of $\mathrm{F}$, so we have the formula:

$$
I_{i}=F^{-1}\left(P_{i}\right)=\beta_{1}+\beta_{2} X_{i}
$$

The Probit model assumes that the error will conform to the normal distribution, in the Probit model, the probability that the dependent variable receives a value of 1 is calculated as follows: 
And the probability that $\mathrm{Y}=0$ will equal 1-Pi.

$$
P_{i}=\frac{1}{\sqrt{2 \pi}} \int_{-\infty}^{B X} e^{-z^{2} / 2} d z
$$

So in the Probit model, we do not study the direct effect of independent variables Xi on Y, but consider the influence of $\mathrm{Xi}$ on the probability that $\mathrm{Y}$ receives a value of 1 or $\mathrm{Y}$ 's expectation.

\section{Research results}

\subsection{Descriptive statistics}

From the sample, $85 \%$ of the children surveyed said they would immediately notify their parents and surrounding adults or immediately to the authorities when being abused. The proportion of boys surveyed in the survey accounts for $47 \%$ and $23 \%$ of children between the ages of 15 and 18 . According to parents' educational level, up to $47 \%$ of the children interviewed have parents with university or higher education; the proportion of children with divorced or separated parents accounted for $13 \%$. Up to $85 \%$ of children surveyed are in urban and rural areas. $93 \%$ of the children surveyed said they had heard about abuse and $74 \%$ of the children said that citizen subjects had already included child abuse in the subject. $77 \%$ of children are equipped with knowledge of child abuse and the remaining $23 \%$ are not equipped. However, only $47 \%$ of children have received training in child abuse prevention and control skills. $72 \%$ of the interviewed children have been taught about child abuse and $75 \%$ of the respondents have been taught self-protection skills.

Table 2. Statistics describing variables in regression model

\begin{tabular}{|c|c|c|c|c|c|c|}
\hline Variable & Explanation & Sample & Mean & Standard deviation & Min & Max \\
\hline \multicolumn{7}{|c|}{ Dependent variable } \\
\hline $\mathrm{Y}$ & What to do when abused & 144 & 0.85 & 0.36 & 0 & 1 \\
\hline \multicolumn{7}{|c|}{ Independent variable } \\
\hline \multicolumn{7}{|c|}{ Individual characteristics of the child } \\
\hline sex & Gender & 144 & 0.47 & 0.50 & 0 & 1 \\
\hline agegroup & Age group & 144 & 0.23 & 0.42 & 0 & 1 \\
\hline school & School & 144 & 0.37 & 0.48 & 0 & 1 \\
\hline area & Area & 144 & 0.85 & 0.35 & 0 & 1 \\
\hline \multicolumn{7}{|c|}{ Personal characteristics of parents } \\
\hline \multicolumn{7}{|c|}{ Education of parents } \\
\hline edum1 & Under University & 144 & 0.22 & 0.41 & 0 & 1 \\
\hline edum2 & University & 144 & 0.47 & 0.50 & 0 & 1 \\
\hline edum3 & Colleges & 144 & 0.09 & 0.29 & 0 & 1 \\
\hline edum4 & Graduate & 144 & 0.23 & 0.42 & 0 & 1 \\
\hline \multicolumn{7}{|c|}{ Marital status of parents } \\
\hline mar_p1 & Get married & 144 & 0.87 & 0.34 & 0 & 1 \\
\hline mar_p2 & Divorce & 144 & 0.08 & 0.28 & 0 & 1 \\
\hline mar p3 & Separated & 144 & 0.05 & 0.22 & 0 & 1 \\
\hline \multicolumn{7}{|c|}{ Education variable on child abuse prevention } \\
\hline nghexamhai & Ever heard of child abuse & 144 & 0.93 & 0.26 & 0 & 1 \\
\hline nd_xamhai & Content about child abuse & 138 & 0.74 & 0.44 & 0 & 1 \\
\hline trangbikt & Equipping knowledge about child abuse & 144 & 0.77 & 0.42 & 0 & 1 \\
\hline skill & Training in skills child abuse prevention & 144 & 0.47 & 0.50 & 0 & 1 \\
\hline dxamhai & Being taught about child abuse & 144 & 0.72 & 0.45 & 0 & 1 \\
\hline skillbv & Being taught about self-defense skills & 144 & 0.75 & 0.43 & 0 & 1 \\
\hline \multicolumn{7}{|c|}{ Practical experience elements } \\
\hline xamhai & Abused & 144 & 0.03 & 0.18 & 0 & 1 \\
\hline
\end{tabular}

\subsection{Research results}

The binary probit regression model that measures children's actions was estimated using the Maximum Likelihood Method. The results of estimating the Probit probability regression model are presented in the table, analytical model that is appropriate and meaningful in the research. The Chi-square test shows that the overall suitability of the model with Prob $>$ Chi $2=0.000$ the factors in the model have an impact on child abuse prevention.

Probit model is a form of non-linear probability model, the estimated coefficients of the regression function in the model do not directly explain the relationship between dependent variables and independent variables that can only be used by sign and meaning level to analyze the direction of influence (positive or negative). Therefore, in order to better understand the impact of the independent variables on the dependent variable, the research team 
calculated the marginal impact coefficient corresponding to each estimation coefficient, and used the coefficient of effect. This is to explain the change of independent variables affecting the impact of education on child abuse prevention and control.

Table 3. Results of analysis of the impact of education on child abuse prevention

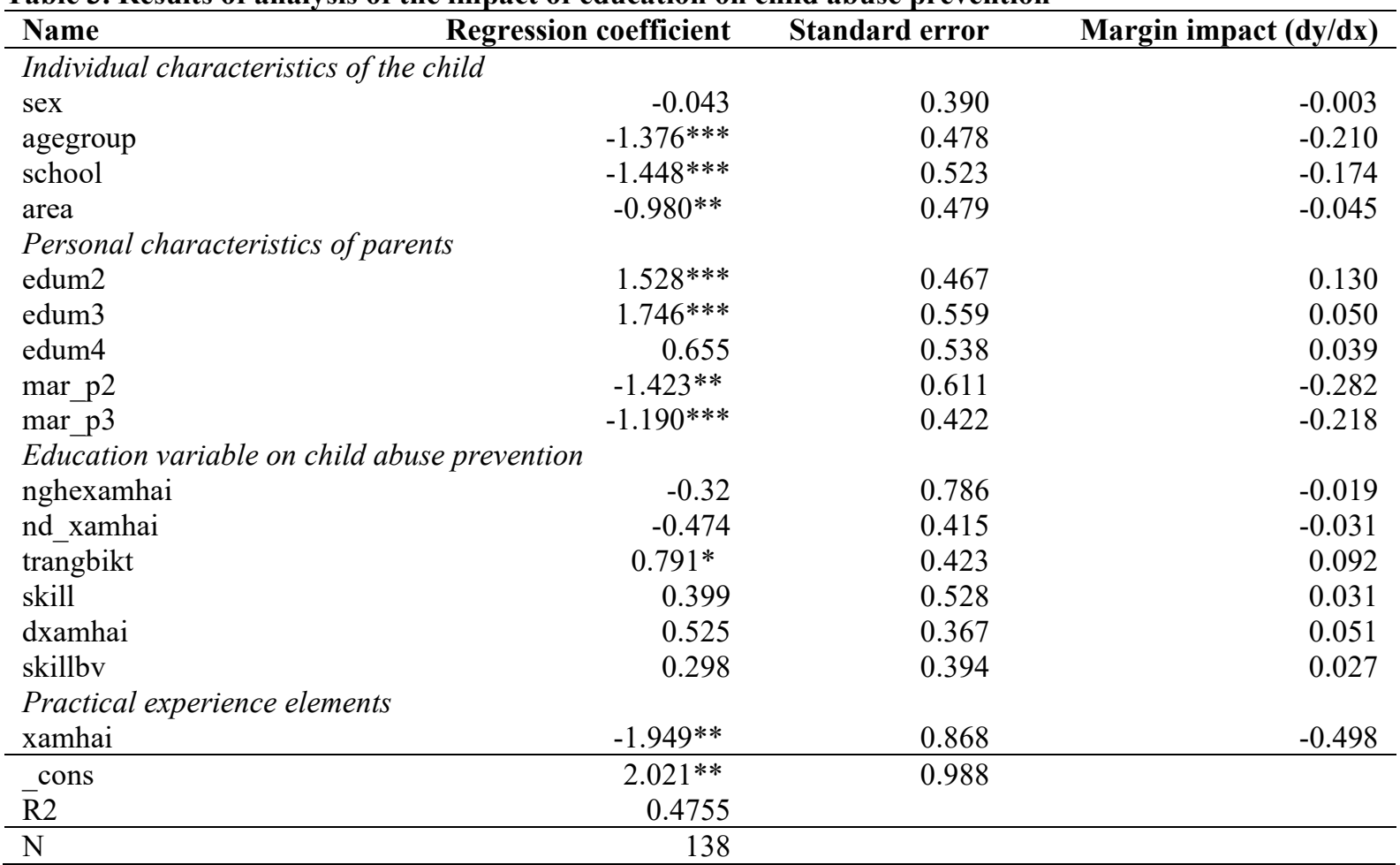

The results of estimating the Probit probability regression model obtained in the above table show that most independent variables are statistically different from 0 at the significance level of $1 \%-10 \%$ and the sign of the estimated coefficients in the model as expected marks - completely consistent with economic theory. The following will examine the specific impact of each factor on child abuse prevention and control.

\section{Group of factors on individual characteristics of children:}

Gender variable: The research results show that the prevention of child abuse is not affected by gender at the significant level of 5\%. This means that there is no difference in the prevention of child abuse among boys and girls.

Age group variables: The estimates of negative age group coefficients show that children aged 15-18 years have lower prevalence of abuse prevention than children with aged 11-14 years old, the lower level was up to $21 \%$ and the coefficient was statistically significant at $1 \%$. It is understandable that at a young age today, attention has been paid to guidance and education on child abuse and how to prevent and abuse children, so that they are better aware than their peers in high school.

Children's school type factor: Research results show that child abuse prevention behaviors in public schools are worse than those in private schools. It may be because private school students are better equipped with knowledge about child abuse than public school students.

\section{Group of characteristics of parents}

Regarding parental education level: the estimated coefficients are positive, this implies that the higher the education of parents, the better the prevention of abuse. At the average value, the education level of the parents at university is likely to immediately notify their parents and surrounding adults or immediately to the authorities when the abuse is higher than their parents with lower university $13 \%$; the same figures for children with parents at college level and above are 5\% and 3.9\% (other factors are unchanged).

Regarding marital status of parents: There is a negative impact on child abuse prevention behavior as expected. According to statistics, children with parents who are divorced or separated are less likely to be abusive than children with married parents.

\section{Education variable on child abuse prevention}

About the factors that have heard about child abuse: Estimates show that children who have ever heard about child abuse have a lower level of abuse against children than they have never heard, but the coefficient. The estimate is not statistically significant at the $5 \%$ level.

Despite the estimated results, children who have learned about child abuse in reading subjects have lower child abuse behaviors than children who have not yet learned, but the coefficient the estimate is not statistically 
significant at the $5 \%$ level. Therefore, it can be concluded that there is no difference in the behavior of child abuse against children to be educated or not to learn the contents of child abuse in ethics.

The fact that children are equipped with knowledge about child abuse has a positive impact on child abuse behavior as expected. This implies that children who have been equipped with knowledge about child abuse are better than children who have never been equipped with knowledge about child abuse.

Factors taught about self-defense skills: Estimated results show that children who have been taught self-protection skills are better at preventing abuse, because children will know be in situations, risks of abuse and have the skills to protect themselves. The estimates are statistically significant at the $5 \%$ level.

\section{Practical experience elements}

Variable that has ever been abused: The estimated results show that each abuse has a negative sign and is statistically significant at the 5\% level. This implies that children who have never been abused will be less vulnerable to abuse than children who have been abused, which is entirely consistent with the theory.

\section{Discussion}

The discussion of results from the quantitative model shows that children who were educated about child abuse prevention take actions when child abuse happened. The result also provides evidence that children who were trained to prevent child abuse become more active in preventing child abuse than who have not been trained. Furthermore, the marital status and educational level of parents have affection on children's ability to address child abuse cases. Children whose parents are married and have high educational level tend to have better practices in child abuse prevention. On the other hand, according to the statistic from government's reports, the number of child sexual abuse cases reached 1421 cases in the first half of 2019. In the meantime, the National Child Protection Hotline received 764 phone calls to report child exploitation cases. The other two forms' data have not been collected yet. This may be due to the recent policies on preventing child abuse in Vietnam. After the explosion of child abuse in media in 2019, the government and public acknowledged this as a serious problem, so they decided to have more strategies and commitment on supporting the government in implementing policies. Thus, with the characteristics of Vietnamese culture: traditional education methods, gaps between generations, fear of being judged, child abuse prevention education should be implemented variegated.

The result of this study provide five recommendations in order to improve the education quality on child abuse prevention:

First, to the children: children have to be aware of all aspects related to child abuse and improve their selfprotection skills. Furthermore, the relationships between children and caregivers should be strengthened and bound together.

Second, to the teachers and parents: having the will to change and improve the educational methods for children in order to create a safe environment and reduce the risks of child abuse. Also, teachers and parents should participate in child abuse prevention training and seek for help from social service agencies.

Third, to the government: there should be more policies enhancing the ability of preventing child abuse for the mass especially children, parents and teachers.

The specific solutions below need to be considered and implemented:

First, establishing a child abuse prevention model to have a clear guidance for different levels of child abuse. An example is the "Public Health Model" which is widely applied in Western countries, including five levels: (i) policies creation with an aim of reducing child abuse risks; (ii) mass advertisement for child abuse prevention; (iii) the child abuse possibilities are narrowed down at risk families; (iv) concentration on abusive families or abused children; (v) recovery services for abused child.

Second, addressing the difficulties of children and families by implementing field conductions into provinces to understand their needs and insight or by creating consultation meetings to define and address caregivers' problems. Third, improving the quality of civic and child abuse prevention education by enhancing the capability of university students in educational field; researching and analyzing international education curriculums to come up with a suitable program for Vietnamese children; developing more courses for teachers and parents; establishing the standards for teachers especially part-time and international teachers.

Fourth, implementing diverse advertising campaigns to enhance the public's awareness. Propagandizing all four types of child abuse in order to fulfill the knowledge of citizen about child abuse. Recently, the society only exposure to two child abuse forms: physical abuse and sexual abuse. If the situation is remained, child abuse prevention process will face up with difficulties in changing the perception of citizen later on. So, all forms of child abuse should be promoted comprehensively. In details, using Vietnam Television as a tool to spread out new messages from the government about child abuse prevention activities; producing more educational shows related to child abuse, etc. Furthermore, optimizing the advantages of social platforms such as Facebook, Youtube to have a friendly approach to the audiences or publishing books in child abuse prevention field.

Fifth, reviewing the Children Law and Criminal Law to examine and strengthen the contexts in order to adapt with the status and ensure the children's rights. For example, reconsidering the age of children and its limitations; 
extending the forms of child abuse; merging the definition of "smut", "intercourse", "rape", "sexual assault" in order to reduce the misunderstanding and confusion; recreating a suitable sanction level for child abuse criminals.

\section{References}

Abrahams, N., Casey, K., \& Daro, D. (1992). Teachers' knowledge, attitudes, and beliefs about child abuse and its prevention. Child Abuse \& Neglect, 16(2), 229-238. https://doi/10.1016/0145-2134(92)90030-U.

Lambie, G.W. (2005). Child abuse and neglect: A practical guide for professional school counselors. Professional School Counseling, 8(3), 249-258.

Bereiter, C. (1970). Child Development and Personality. The Educational Forum, 34(3), 434-435.

Ministry of Labor, War Invalids and Social Affairs (2019). Month of Action for Children 2019.https://thukyluat.vn/vb/thong-tu-28-2019-tt-bldtbxh-to-chuc-thang-hanh-dong-vi-tre-em-69dc9.html

Center for Excellence in Child and Family Welfare Inc (2017). Response to the Victorian Government's Lookout Education Support Centre consultation paper.

Chen, J., Dunne, M. P., \& Han, P. (2007). Prevention of child sexual abuse in China: Knowledge, attitudes, and communication practices of parents of elementary school children. Child Abuse \& Neglect, 31(7), 747-755. DOI: 10.1016/j.chiabu.2006.12.013

Department of Children - Ministry of Labor - Invalids and Social Affairs (2019). Summary of reports of provinces and cities.

Daro, D. A., \& Cohn-Donnelly, A. (2002). Child abuse prevention: Accomplishments and challenges. In J. E. B. Myers, L. Berliner, J. Briere, C. T. Hendrix, C. Jenny, \& T. A. Reid (Eds.), APSAC handbook on child maltreatment (2nd ed., pp. 431-448). Thousand Oaks, CA: Sage Publications

Deblinger, E., Thakkar-Kolar, R. R., Berry, E. J., \& Schroeder, C. M. (2009). Caregivers' Efforts to Educate Their Children About Child Sexual Abuse. Child Maltreatment, 15(1), 91-100. https://doi.org/10.1177/1077559509337408

Dewey, J. (1916). Democracy and Education, An Introduction to the Philosophy of Education. New York, Macmillan. DOI: 10.12691/education-2-12A-6

Finkelhor, D., \& Korbin, J. (1988). Child abuse as an international issue. Child Abuse \& Neglect, 12(1), 3-23. https://doi.org/10.1016/0145-2134(88)90003-8

Gershoff, Elizabeth T. (2010). "More harm than good: a summary of scientific research on the intended and unintended effects of corporal punishment on children." Law and Contemporary Problems, 73(2), 31-42.

Goldman, J. D. G., \& Bradley, G. L. (2011). Assessing primary school student-teachers' pedagogic implementations in child sexual abuse protection education. European Journal of Psychology of Education, 26(4), 479-493. DOI: 10.1007/s10212-011-0059-4

Higgins D, Bromfield L \& Richardson N (2006). Child abuse prevention: what works? The effectiveness of home visiting programs for preventing child maltreatment. National Child Protection Clearinghouse Research Brief 2, 16 pages.

Holly, B., Andy, B., Maria, H., Pooja, K., Niamh, M., Orla, O. and Jessica, P. (2019) How safe are our children? An overview of data on child abuse online. NSPCC Learning.

Idris, F., Hassan, Z., Ya'acob, A., Gill, S. K., \& Awal, N. A. M. (2012). The Role of Education in Shaping Youth's National Identity. Procedia - Social and Behavioral Sciences, 59, $443-450$. https://doi.org/10.1016/j.sbspro.2012.09.299

Lambie, G.W. (2005). Child abuse and neglect: A practical guide for professional school counselors. Professional School Counseling, 8(3), 249-258.

Lewis, E. M., Feely, M., Seay, K. D., Fedoravicis, N., \& Kohl, P. L. (2016). Child Welfare Involved Parents and Pathways Triple P: Perceptions of Program Acceptability and Appropriateness. Journal of Child and Family Studies, 25(12), 3760-3770.

Marion, M. (1982). Primary Prevention of Child Abuse: The Role of the Family Life Educator. Family Relations, 31(4), 575. DOI: $10.2307 / 583935$

McEachern, A. G., Aluede, O., \& Kenny, M. C. (2008). Emotional Abuse in the Classroom: Implications and Interventions for Counselors. Journal of Counseling \& Development, 86(1), 3-10.

McElvaney, R. (2013). Disclosure of Child Sexual Abuse: Delays, Non-disclosure and Partial Disclosure. What the Research Tells Us and Implications for Practice. Child Abuse Review, 24(3), 159-169. https://doi.org/10.1002/car.2280

Meadow, R. (1989). ABC of child abuse. Epidemiology. BMJ, 298(6675), 727-730. 10.1136/bmj.298.6675.727

O'Donnell, M., Scott, D., \& Stanley, F. (2008). Child abuse and neglect - is it time for a public health approach? Australian and New Zealand Journal of Public Health, 32(4), 325-330. 10.1111/j.1753-6405.2008.00249.x

O'Toole, R., Webster, S. W., O'Toole, A. W., \& Lucal, B. (1999). Teachers' recognition and reporting of child abuse: a factorial survey. Child Abuse \& Neglect, 23(11), 1083-1101.

Pfohl, S. J. (1977). The "Discovery" of Child Abuse. Social Problems, 24(3), $310-323$. 
https://doi.org/10.2307/800083

Congress, Law number 25/2004/QH1 1 about Protection, care and education for children. Hà Nội, 15th June, 2004. http://vaac.gov.vn/vanban_detail/Detail/Luat-Bao-ve-cham-soc-va-giao-duc-tre-em

Saunders B, Goddard C. (2017). The role of mass media in facilitating community education and child abuse prevention strategies. Child Family Community Australia 2002 [Retrieved 24 August 2019]. Available from: https://aifs.gov.au/cfca/publications/role-mass-media-facilitating-community-education.

General Statistics Ofice - Vietnam (2014). Multiple Indicator Cluster Survey 2014

Umobong, M. (2010). Child Abuse and its Implications for the Educational Sector in Nigeria. OGIRISI: a New Journal of African Studies, 7(1), 15-21.

UNICEF (1989). Convention on the Rights of the Child

Wurtele, S. K., Kast, L. C., \& Melzer, A. M. (1992). Sexual abuse prevention education for young children: A comparison of teachers and parents as instructors. Child Abuse \& Neglect, 16(6), 865-876. https://doi.org/10.1016/0145-2134(92)90088-9 